\title{
A semantic analysis of dual voice in a literary style ${ }^{\dagger}$
}

\author{
Ștefan Oltean* \\ Faculty of Letters, "Babeș-Bolyai" University, Str. Horea 31, 400202 Cluj-Napoca, Romania
}

\section{Article info}

History:

Received November 17, 2015

Accepted November 26, 2015

Published February 12, 2016

Key words:

dual voice

discourse

\begin{abstract}
This article proposes an account of dual voice in free indirect discourse (FID), a point-of-view narrative style used mainly in literary narrative for the representation of verbal events, and of verbal or non-verbal mental events (see Oltean, 1993). First, it sums up in a nutshell the issue of what constitutes FID, without dealing in detail with what distinguishes it from "normal" indirect discourse and direct discourse (see, for this matter, Ehrlich, 1990; McHale, 1978; Oltean, 1993). Next, it addresses the issue of dual voice associated with this discourse mode, after which it gives an outline of the analytical framework. Finally, it provides a description for an FID sentence selected from English literary prose, with a view to furnishing evidence for its dual nature.
\end{abstract}

\section{Introduction}

Free indirect discourse (FID) is a discourse mode used especially in literary narrative for the representation of verbal events and of verbal or nonverbal mental events. Various approaches have led to limited accounts of FID, addressing either its linguistic characteristics, or its semantic and pragmatic functions, but except for Doron (1991) and Oltean (2003) they have not given an explicit formulation of its dual nature.

In what follows, I offer first a brief characterization of FID (see also McHale, 1978 and 1983; Oltean, 1993; Ehrlich, 1990; and Flundernik, 1999), after which I address the issue of dual voice coupled with this discourse mode, sketch the analytical framework and provide a semantic analysis of an FID sample. On my view FID is not, in principle, a type of "report," but basically a mode of "representation" - a broader category that subsumes not only the rendition of verbal events, but nonverbal mental events as well. The database for the article consists of excerpts from literary texts by Virginia Woolf (To the Lighthouse and Mrs Dalloway), D. H. Lawrence (The Rainbow, Women in Love) and Doris Lessing (To Room Nineteen).

As compared to other modes, FID displays an atypical structure: while preserving the original syntax of direct discourse (DD) (it is "free", showing signs of syntactic autonomy, as illustrated in (1) by the subject/auxiliary-verb inversion), it is also constrained by tense and person agreement like indirect discourse (ID). Its "blended" nature (Kuno, 1986) has challenged and continually baffled linguists and stylisticians, thus generating the great variety of approaches that have been taken to it. The following is an example of FID (italics) in a passage from The Rainbow (Lawrence, 1934, p. 10):

(1) Why should the curate's children inevitably take precedence over her own children...? It was education and experience, she decided.

Its marking in the immediate verbal context can include inquit formulas or parentheticals containing verbs of communication (to say, to ask, to answer, etc.), psychological verbs, or verbs of perception (to think, to feel, to wonder, to hear, etc.), but such indices are not obligatory. When they occur, they are external to the FID structure, being separated from it by commas (e.g., "she decided," above) or even by parentheses, as in the following passage from Mrs Dalloway (Woolf, 1964, p. 37):

\footnotetext{
${ }^{\dagger}$ This paper contains material from my articles $A$ Survey of the Pragmatic and Referential Functions of Free Indirect Discourse (Oltean, 1993) and On the bivocal nature of free indirect discourse (Oltean, 2003).

*Email address: stefan.oltean@ubbcluj.ro.
} 
(2) But this question of love (she thought, putting her coat away), this falling in love with women.

Sections of this kind can be dislocated in sentence-medial or -final position, and, as statements or commentary about the represented verbal or mental events, they can, among other things, block the sentence from being interrogative. However, such a DD structure (question) can be employed in the FID portion (which is evidence of its syntactic autonomy) or can mark the entire sentence if dislocation is in sentencemedial position. This suggests that inquit formulas are not part of the FID $^{1}$, but external to it. True imperatives appear to be barred from FID in English, or at least their discourse mode is sufficiently ambiguous that they may just as well be in DD. Consequently, (3) and (5) are unacceptable as FID sentences (they ought to be declarative, although (5) would be acceptable as DD if the absence of quotation marks were ignored), (7) has an ambiguous discourse mode status (imperative in FID or rather-given the impossibility of co-indexing the pronominals -in DD), while (4) and (6), from Mrs Dalloway (Woolf, 1964, p. 41) and To the Lighthouse (Woolf, 1932, p. 119), respectively, are acceptable (see Oltean, 1993):

(3) *What would he think when he came back, did she wonder?

(4) What would he think, she wondered, when he came back?

(5) How did she $e_{\mathrm{i}}$ manage these things in the depth of the country, ask her ${ }_{*_{\mathrm{i}} / \mathrm{j}}^{2}$.

(6) How did she $e_{\mathrm{i}}$ manage these things in the depth of the country? he asked her $\mathrm{r}_{\mathrm{i}}$.

(7) Well then let her ${ }_{\mathrm{i}}$ go and be damned to her, she $_{\mathrm{j} /{ }^{*} \mathrm{i}}$ told herself.

The usefulness of delimiting FID from other sentence constituents is demonstrated by the intriguing complexity of its structures, which indicates the productivity of a pattern that enjoys relative syntactic independence.

As shown above, FID displays a "blended" nature (Kuno, 1986). On the one hand, its marking like DD may be interpreted as being for the character or protagonist since it evokes a voice or perspective different from the narrator's; this also involves the occurrence of idiosyncratic lexical elements such as colloquialisms, slangy words, or of lexical items belonging to various [nonliterary] registers, as well as the presence of the indexicals this, here, now, of emotive language, of exclamations, or of the interrogative subject/auxiliary-verb inversion. On the other hand, its marking like ID may be taken to be associated with the narrator, at least as a "formal speaker" (Ehrlich, 1990, p. 9) (third-person pronoun with first person deixis, special tense system based on past-tense verb forms with possible present and future time deixis). This conjunction of features that sustain the "obliqueness" (Strauch, 1974) of FID sentences (i.e., tense and person agreement) with the presence of elements that mark the character's voice signals the bivocality (Bakhtin, 1973) or polyvocality (McHale, 1978) of FID and, implicitly, the dual perspective that it articulates. Semantic peculiarities, such as the simultaneous presence of outer and inner perspective, have also been suggested (Cohn, 1978), and the significance of major semantic and pragmatic factors, such as irony and context, has been highlighted (see Ramazani, 1988; Weinberg, 1981, 1984; McHale, 1983; Oltean, 1993). Mikhail Bakhtin [V. N. Voloshinov] (1973, p. 155) contends, in this respect, that what distinguishes FID is the fact that both author and character speak at the same time, that the character's accents or intonations (empathy) coexist with the author's accents (distance) in the same linguistic construction. In addition, Moshe Ron (1981) postulates particular types of FID representations of "echo questions," specified as embedded dialogue, which yield two superimposed speech acts— the "reporting" speech act of the narrator and the "reported" speech act of the character-, and thus, two speakers ${ }^{3}$. In

\footnotetext{
${ }^{1}$ But see Kuno (1986), who, contrasting Japanese "blended discourse” with English "quasi-indirect discourse" (i.e., "free indirect discourse"), tends to treat the contiguous contextual indices in English as part of the quasi-indirect discourse. See also Susan Ehrlich's (1990) account of FID, where the role of parentheticals is reassessed from a discourse analytic perspective.

${ }^{2}$ The subscript letters mark the possibility or impossibility of co-indexing specific pronominals in the main clause structure with pronominals in the parenthetical structure, i.e., they mark the identity and the nonidentity, respectively, of their reference. In the first case (identity), we have sentences acceptable as FID; in the second case (nonidentity), sentences unacceptable as FID.

${ }^{3}$ Ron (1981, p. 31-32) argues that the sentence "What had kept her?" (an echo question represented in FID in an analyzed
} 
a balanced approach, Vaheed Ramazani (1988, p. 43) indicates that the role of no one particular kind of "index" among those that contribute to the perception of FID as "a fusion of narratorial and figural language" should be exaggerated, since their relative importance is dictated by each particular case, which underscores the importance of context, while elsewhere, e.g., (8), from "To Room Nineteen" (Lessing, 1981 , p. 55), syntactic or lexical features, such as exclamations, intensifying adverbs, or subject/auxiliary inversions, prevail.

(8) But then everyone exclaimed: Of course! How right! How was it he never thought of it before?

Polyvocality can be observed in the following passage from To the Lighthouse (Woolf, 1932, p. 162-163), where it pervades the representation of external speech through FID:

(9) They came with their brooms and pails at last; they got to work. All of a sudden, would Mrs McNabb see that the house was ready, one of the young ladies wrote; would she get this done; would she get that done; all in a hurry. They might be coming this summer.

Here, the housekeeper's (Mrs. McNabb's) external discourse is represented. The polyvocality is inherent in the dramatic irony, expressed by the specific accentuation and concentration of colloquialisms in a condensed version of the speech event, ascribable to the narrator. The verb tenses and the pronouns sustain a distancing effect, which is also associated with the narrator.

Polyvocality may consist, however, in a mere emphatetic identification of the narrator with the character, which quite often marks the representation of the character's own reflections, as in (10), from The Rainbow (Lawrence, 1934, p. 274).

(10) Why, oh why must one grow up, why must one inherit this heavy, numbing responsibility ofliving an undiscovered life? Out of the nothingness and undifferentiated mass, to make something of herself!

Here, the FID conveys the narrator's sympathy for the self-pitying character. The example might suggest that polyvocality has been abolished; however, even in this case, FID contains signs of the narrator: notably, tense and person agreement, as well as the highly articulated rendering of the internal states.

At the opposite pole, as if defying sweeping generalizations, there is FID that tends to be univocal. This happens especially when FID, functioning as a vehicle of spontaneous, non-reflective consciousness, represents nonverbal or preverbal mental states, usually perceptions, as Kuroda (1976) and Banfield (1982) maintain; according to them FID consists of "unspeakable sentences," being a particular, sui generis, mode of language, that defies handling within a communicational framework ${ }^{4}$. Vocalization creates in this case a percept ascribable only to the narrator, but once the representational conventions of language and

example from Henry Miller's Sexus) can be reconstructed as a dialogue between the narrator (Henry) and the character (Mara), later embedded in a FID report:

Henry: What kept you?

Mara: What kept me?

Therefore, the sentence consists of two distinct, superimposed speech acts by two speakers: a "reporting" (narrator) and a "reported" (character). The latter is presupposed by the former's use of "her," indicating a referent other than himself, at the level of the pragmatic context represented in the text-the person who provoked the question.

${ }^{4}$ Kuroda and Banfield elaborate an interpretation according to which the semantic peculiarity in question is indexical of FID sentences: narratorless or speakerless, they merely enact a state of mind, something that is "unspeakable" and cannot therefore be cast into a communicational framework. Banfield (1982) distinguishes, on the basis of the presence or absence of various syntactic and lexical features (e.g., expressive elements, such as exclamations, repetitions, questions, etc., personal pronouns, deictics, tense, particular lexical expressions), sentences of represented speech and thought, or FID (noncommunicative, expressive), from those of narration (noncommunicative, nonexpressive) and discourse (communicative, expressive), and labels the first two types "unspeakable sentences." While narration is neither a communicative use of language (i.e., the use defined by the $I /$ you relation) nor an expression of subjectivity, FID is "expressive," but speakerless, since the "subjective" elements, or "expressions," are coreferent with a third-person "subject-of-consciousness" (Banfield, 1982, p. 18) and not with a speaker, whose marking would have to be an $I$ (sic!). For Kuroda, likewise, sentences of FID are noncommunicational, being ascribable 
literature are accepted, the discourse is readily presumed to render the character's personal experience, including his or her subjectivity.

The issue of dual voice or perspective is thus controversial in the literature. Given this controversy, a formalization of the dual voice would be welcome, since it would contribute to the settling of the dispute by clarity and simplicity. Doron (1991) is the first to suggest an explicit formulation of this phenomenon, in a relevant contribution from the point of view of situational semantics. Dissociating point of view as a factor of content from attitude, she argues that some deictic or indexical expressions are sensitive to the discourse situation - e.g., first- and second-person pronouns, see (11) -, some depend on the point of view or perspective-e.g., demonstratives, temporal deictics; see (12) -, from The Rainbow (Lawrence, 1934, p. 377]), while others are sensitive to both discourse situation and point of view-e.g., third person pronouns, tense; see (13), from The Rainbow (Lawrence, 1934, p. 350).

(11) I hate it. ["I" is a function from contexts to intensions; its value is given by the discourse situation: the speaker.]

(12) She felt she must go out of this school, this torture place. [The value of "this school" and "this torture place" is sensitive to the character's point of view (Ursula), not to the discourse situation (speaker, location of discourse); it denotes an entity contemplated by the subject-of-consciousness (Ursula) - the school in question; its value is a function from point of view to intensions.]

(13) [a] As she returned home, she dreamed again ... her old, gorgeous dreams. [b] One of her applications was to Gillingham, in Kent ... [The value of "her" (Ursula) in (a) is distinct from the speaker (the narrator), it being anchored to the discourse situation; the same holds good for the verb tense-past-, which anchors to speech time (present). However, in (b), which is in FID, the value of "her" is a function of the represented point of view, being identical with the subject-of-consciousness (Ursula), as is also the case with the tense-past-, which does not anchor to speech time (present), but to the character's point of view, denoting present time (the represented state of affairs is simultaneous with the character's act of mentation).]

With regard to the third-person pronouns in FID which function as subjects-of-consciousness (see, e.g., "her" in (13b), Doron (1991) observes that they contain additional gender information which could not be attributed to the protagonist, since the latter would refer to himself or herself as "I" (i.e., " $m y$ applications," not "her applications," in our example). Thus, these pronouns "are more informative" than "I," she concludes (p. 59), and proposes that the information in question emerges from the situation of the narrator (p. 60). This is taken as evidence for the dual voice position, since, while the character's voice "emanates" from the point of view, the narrator's voice "emanates" from the discourse situation. Illuminating as it may be, there is a problem with this demonstration: FID requires a marking in the third person-with which the point of view is associated-, and a language like English cannot avoid gender marking in the singular in this person; so, forms like "she" or "he," "her" or "his" are the only possibilities offered by the language. Likewise, there are languages that have no distinct gender forms for third person pronouns (e.g., Hungarian). Consequently, the additional gender information contained in the thirdperson pronouns might not be decisive evidence for the presence of dual voice.

Therefore, I consider that new evidence for the dual nature of FID is necessary, which I will try to furnish by using a somewhat different framework, namely a model-theoretic semantics framework or possible world semantics framework. My hypothesis is that an account from this perspective can capture referential aspects having to do with the situations or states of affairs themselves described by FID, and can thus furnish evidence for the dual voice sustained by this mode.

to the constitutive or poetic function of language. Such sentences display a nonassertive structure since they do not quote or report the discourse (external or internal) of an original speaker and do not issue from any addresser. Moreover, they are not grounded on any intentional mental act of evaluation on the part of the character, which would require a first-person marking, but merely represent a state of mind (including its expressivity) or an intermediate level of consciousness, namely, spontaneous, non-reflective consciousness. In other words, they create the knowledge of an event (i.e., a character's action or his/her inner state), but lack "semiotic motivation" (see Ron, 1981) since they have no marking for a (real or imaginary) transmitter. 


\section{FID and the referential question}

In Oltean (1993) we have shown that FID - as a discourse mode used especially in literary narrative for the representation of verbal events, and of verbal or non-verbal mental events-is about a discursive act (external or internal discourse) in a world of fiction, or about an act of mentation belonging to the character's spontaneous, non-reflective consciousness (psychological fact). Now, in order to give an account of the dual nature of FID, I turn to consider the question of how the reference, truth value or denotation of literary FID is constituted, since the issue of bivocality involves a referential side: if FID is not singlevoiced, if it displays a marking for the narrator in addition to the character, then it is about two worlds: a world compatible, e.g., with what the character says, thinks, imagines, etc., and a world where what the narrator tells is actualized. For this purpose I will briefly address the notion of reference within modeltheoretic semantics, and will consider versions of this type of semantics, such as the ones presented in Chierchia \& McConnell-Ginet (2000) and Portner (2005), which I will adapt for discussing referential or extensional aspects of FID.

Since Gottlob Frege, the notion of reference has been accounted for in terms of a relation between linguistic expressions and their denotata ${ }^{5}$, and such terms have also been used as denotation, semantic value or truth-value, the first two being reserved for what a name or some other expression denotes, while truth-value has been used for the reference of sentences - the situations or states of affairs they denote (see Chierchia \& McConnell-Ginet, 2000, and Portner, 2005). The cited versions of formal semantics provide a formalized specification of the denotation of linguistic expressions or sentences in an artificial language called predicate calculus (PC) by producing descriptions of the mental representations that we associate with them, which are then assigned a truth value by means of the interpretation function [[]]. The interpretation is relativized to a model $M$ or "world" for the language-which the different kinds of expressions in the language (variables, individual constants, predicates) refer to-and an assignment $g$ of values to variables. The model is an abstract structure of the form $\langle U, V\rangle$, where $U$ is the domain or set of individuals or universe of discourse and $V$ is a function that assigns an extension in $U$ to the individual constants and predicates of PC. The PC also contains a set of recursively specified semantic rules which provides a way of computing the truth values of sentences relative to the content of the model. If $S$ is a true sentence, its value is formalized as $[[S]]^{M, g}=1$, which says that $S$ is true relative to $M$ and assignment $g$ (see Chierchia \& McConnell-Ginet, 2000, p. 125); if it is false, 0 is used for its truth value. So the value of the sentence $[[S \text { The Chancellor of Germany is a woman }]]^{M, g}=1$ if and only if (iff), after assigning semantic values relative to $M$ and $g$ to the lexical items, and giving the combinatorial rules, it is possible to evaluate $S$ as true relative to $M$ and $g$. By the semantic rules of a fragment of English this is the case iff $[[\text { the Chancellor of Germany }]]^{M, g} \in[[\text { woman }]]^{M, g}$, that is, iff the Chancellor of Germany is a member of the set of women or, in other words, of the set that constitutes the extension of the predicate is a woman in the specified situation. If these conditions do not obtain, $[[S]]^{M, g}=0$.

Such an account specifies the truth conditions of sentences in terms of the referential value of their components in a given situation, and different models can specify different situations, but only one such situation can be considered in evaluating a sentence. There are, however, many linguistic expressions or sentences that require an evaluation in circumstances different from the ones in which they are evaluated, for example relative to past or future situations, or to possible, non-actual or hypothetical situations. Such expressions describe possible worlds or alternative circumstances_ “a way things might be, not necessarily the way they are" (Lewis, 1979, p. 84). They are intensional constructions, whose extension can be specified by selecting a world or time coordinate, relative to which semantic values or truth values can be assigned, as the examples below illustrate:

${ }^{5}$ See Chierchia \& McConnell-Ginet (2000, p. 65), who indicate that according to Frege the reference is what the expression stands for on a given occasion of its use, while its sense is the way in which the reference is presented. 
(14) $[[\text { president of America }]]^{w_{@}, t_{0}}=$ Barack Obama $\left[\right.$ where $w_{@}$ is the actual world, and $t_{0}$ is speech time]

(15) $\left[[\text { president of America] }]^{w_{@}, t_{1}}=\right.$ George W. Bush [where $t_{1}$ precedes $t_{0}\left(t_{1}<t_{0}\right)$, e.g., $t_{1}=$ October 31, 2008]

(16) $[[\text { president of America }]]^{w_{1}, t_{0}}=$ Mitt Romney [where $t_{0}$ is speech time, and $w_{1}$ is a possible world in which Mitt Romney wins the elections]

(17) $[[\text { Mitt Romney is president of America] }]]^{w_{1}, t_{0}}=1$ [where $t_{0}$ is speech time, and $w_{1}$ is a possible world in which Mitt Romney wins the elections; the sentence is true in $w_{1}$ at speech time iff Mitt Romney wins the elections in $w_{1}$ ]

Truth conditions change, however, in the case of embedded complement clauses of verbs of propositional attitude, such as believe, think, hope, which are are relevant for the analysis of FID. Let us consider, to this effect, (18) below:

(18) $[[\text { Paul believes that Mitt Romney is president of America }]]^{w_{\circledast}, t_{0}}=1$ iff Paul believes that Mitt Romney is president of America, according to Tarski’s discitational principle (, $\varphi$ " is true iff $\varphi)$.

As can be seen, the truth value of (18) does not depend on the truth of the embedded clause, since the latter is assigned a truth value not in the actual world where the sentence is produced but in a world compatible with what Paul believes, or in Paul's belief worlds, see (19):

(19) $\left[\left[\text { Paul believes that }[[\text { Mitt Romney is president of America }]]^{w_{1}, t_{0}}\right]\right]^{w_{@}, t_{0}}\left[\right.$ where $w_{1}$ is a world compatible with what Paul believes (in this world Mitt Romney is president of America).]

The model $M$ will now be a tuple $\langle W, T,<, U, V\rangle$, where $W$ is a set of worlds, $T$ is a set of times ordered by the relation of precedence $<$ (such that $t_{2}<t_{1}$ is read " $t_{2}$ is prior to $t_{1}$ "), $U$ is defined as the domain of "quantification," and $V$ is a function from individual constants and predicates to intensions in $W$ and $T$ (circumstances) (see Chierchia \& McConnell-Ginet, 2000, p. 268). In particular, for verbs taking that clauses, such as believe, $V$ will be a function from worlds and times into two-place relations, the first member being an individual in $U$, the second member a proposition or a set of worlds (p. 304). The new intensional predicate calculus, which now contains an interpretation function of the form $[[]]^{M, w, t, g}$, will assign a truth value to a sentence with respect to a model and an assignment function as well as a world-time pair, by associating it with some proposition that is evaluated as true or false relative to the particular circumstance defined by the coordinates $w$ and $t$.

These aspects are relevant for the semantics of FID, since its sentences are often coupled with parentheticals that contain verbs of propositional attitude-e.g., psychological verbs or performative verbs, such as decide in (1), think in (2), wonder in (4), dream in (13), exclaim in (8), ask in (6). However, since our analysis is based on literary FID, the coordinates in terms of which semantic values are assigned need to be adjusted by taking into account specifics of literary fiction, despite the deep issues raised by an application of possible worlds semantics to the description of this type of discourse (see Currie, 1990; Lewis, 1983; Pavel, 1986).

Narrative fiction presupposes recentering (Ryan, 1991), by which a story world takes the place of the actual world. Narrative fiction can thus be viewed as an alternative system that displays a central world around which there are peripheral worlds accessible from this central world. Its reference depends on what is in the story or rather in a world compatible with the story - a possible world according to Lewis (1983) and Currie (1990, p. 62), where the text of the story or what is explicit in the story is told as "known fact," that is, is taken to be true.

To represent FID, whose coupling with narrative fiction is uncontroversial ${ }^{6}$, coordinates will thus have to be defined relative to circumstances in the worlds of the story or in the (peripheral) worlds accessible

\footnotetext{
${ }^{6}$ There seems to exist a consensus among scholars on this point. See also Cohn (1978) and Fleischman (1990), who are of the opinion that FID, although not restricted to the literary, is a phenomenon characteristic of narrative fiction.
} 
from the worlds of the story. Now, if $w_{1}$ is a world compatible with the story or a story world which replaces the actual world, and $t_{1}$ the narrator's speech time, then $w_{2}$ will be a world accessible from $w_{1}$, compatible with what a protagonist character in a narrative episode thinks, dreams, imagines etc. (Figure 1). Furthermore, $t_{2}$ will be the reference time or narrative present- "timeline in which fictional events occur" (Ehrlich, 1990, p. 64) -, while $t_{3}$ will be the time of an event or state prior to $t_{2}$. These symbols will enable us to capture the dual nature of the FID fragment in the selected example.

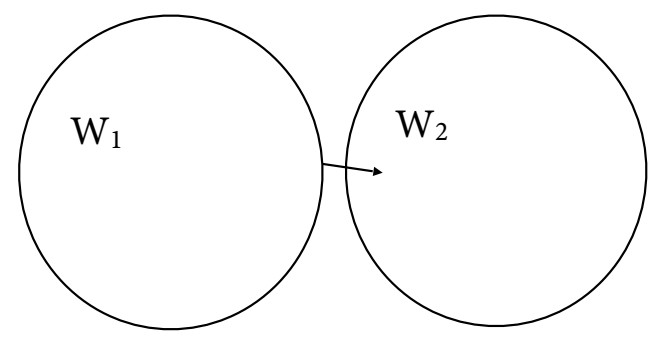

Figure 1

\section{Analysis}

FID sentences contain, as a rule, parentheticals or controlling predicates. They are often not explicit, but they can be supplied by considering the type of verbal act or act of mentation represented (question, exclamation, conversation, reflection, retrospection, etc.). This allows an unambiguous description of the referential aspects, enabling the treatment of the FID portions of complex sentences or of entire FID sentences as "complements" of the controlling predicates, and the subsequent specification of their denotation in a story world or world accessible from the story. For the purposes of the analysis I therefore take FID sentences or portions thereof (when the entire sentence is not in the FID mode) to be extensionally like "embedded" constructions ${ }^{7}$, despite syntactic differences from such clauses, or semantic distinctions issuing from its dual feature.

Furthermore, the parenthetical predicates can be treated in terms of factivity and nonfactivity (see Kiparsky \& Kiparsky, 1971), which are associated with transparency with regard to presuppositions of their complements, and, respectively, opaqueness (see Karttunen, 1991, p. 410). The former (factives) include verbs like realize, notice, remember ${ }^{8}$; they presuppose that their complements are true, which can be checked, e.g., by negation, as in (20):

(20) (a) John realizes that he is wrong.

(b) John does not realize that he is wrong.

Here, realizes presupposes that "John is wrong" is true, since it is preserved under negation in (20b). The nonfactives, which do not presuppose that their complements are true, include, among other categories of verbs, various verbs of saying and inquisitive verbs (e.g. say, tell, ask), "world creating" verbs (e.g., dream, imagine), or psychological verbs (e.g., believe, think) (see also Karttunen, 1991 for kinds of complementizable verbs). I will assume that when the truth of the FID portion is entailed by the larger discourse structure or sentence with parenthetical that contains it, as is the case with factives, the FID construction is assigned a truth value in a story world; when it is not entailed, its truth value needs to be assigned relative to some other world or world and time, e.g., in worlds accessible from a story world.

In what follows, I propose a formalization of the dual voice structure of the FID in (21), selected from Women in Love (Lawrence, 1977, p. 216). In doing this, I employ the sematic framework outlined above

\footnotetext{
${ }^{7}$ In her account of FID, Ehrlich (1990) makes a somewhat similar assumption.

${ }^{8}$ For the purposes of the analysis, I ignore Karttunen's (1991) distinction between factives and semi-factives. Likewise, I operate with the notion of semantic presupposition; for a discussion concerning pragmatic aspects of presupposition and the problematic logical status of presuppositions see, e.g., Karttunen (1991).
} 
and the adaptations of coordinates to the circumstances in the worlds of fiction or in the (peripheral) worlds accessible from the central worlds of the fiction.

(21) [a] Tomorrow was Monday. [b] Monday, the beginning of another school-week!

The dual nature of the FID in this example can be demonstrated by assigning semantic values to three linguistic expressions in [a]: "tomorrow," "was" and "Monday." For an adequate interpretation, however, this sentence requires the postulation of a parenthetical expression containing a non-factive predicate, such as Ursula thought, where Ursula is the protagonist character. Since the parenthetical predicate does not presuppose the truth of the complement clause in a world in which the sentence is produced but in a world in which what the character thinks is actualized, tomorrow is assigned a semantic value by the formula

(22) $[$ tomorrow $]]^{M, g, w_{2}, t_{2}}$ [where $w_{2}$ is a world compatible with what the character thinks, and $t_{2}$ is a time of the character's reflection (prior to the narrator's speech time, $t_{1}$ ); in other words, "tomorrow" is sensitive to the character's point of view].

The second expression, was, gets a value by the formula

(23) $[[\mathrm{was}]]^{M, g, w_{1}, t_{1}}$ [where $w_{1}$ is a story world and $t_{1}$ is the narrator's speech time, which anchors the tense (past) of the verb].

The third expression, Monday, gets a value by the formula

(24) $[[\text { Monday }]]^{M, g, w_{2}, t_{2}}$ [According to it the value of Monday is "the day that follows the interval containing $t_{2}$, and which is a day called 'Monday' "; "Monday" anchors to the character's (Ursula's) time of reflection, $t_{2}$, which is prior to the narrator's speech time, $t_{1}$.]

The dual nature of this stretch of discourse is demonstrated by the fact that the verb was depends for its tense (past) on a time, $t_{1}$, of the narrator's act of telling, and is, therefore, about a world in which what the narrator tells is actualized, while tomorrow and Monday depend for their value on a time, $t_{2}$, of the protagonist's reflection $\left(t_{2}<t_{1}\right)$, and designate an interval or a day called "Monday," in a world, $w_{2}$, compatible with what the protagonist thinks. So the FID in [a] is about two worlds: a world compatible with what the character thinks $\left(w_{2}\right)$ and a story world $\left(w_{1}\right)$, which the narrator describes (see Figure 2, which illustrates that the FID representations are at the locus of the intersection of the two worlds).

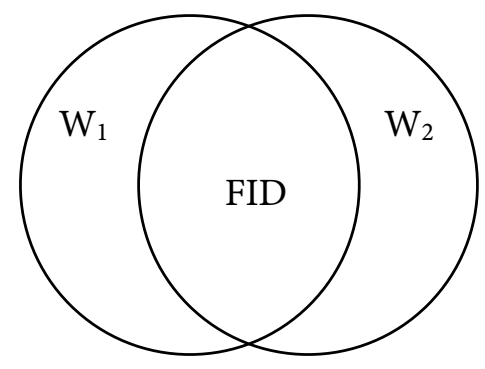

Figure 2

\section{Conclusions}

The analysis within a framework of possible world semantics has furnished evidence for the dual voice or perspective associated with FID, indicating that the latter can be about two worlds, namely a world compatible with what the character thinks, contemplates, etc. and a story world, which the narrator describes. 


\section{Bibliography}

Bakhtin, M. [V. N. Voloshinov] (1973). Marxism and the Philosophy of Language, Seminar Press, New York - London, CrossRef.

Banfield, A. (1982). Unspeakable Sentences, Routledge and Kegan Paul, London, CrossRef.

Chierchia, G. \& McConnell-Ginet, S. (2000). Meaning and Grammar: An Introduction to Semantics, MIT Press, Cambridge, MA.

Cohn, D. (1978). Transparent Minds, Princeton University Press, Princeton, NJ.

Currie, Gr. (1990). The Nature of Fiction, Cambridge University Press, Cambridge, CrossRef.

Doron, E. (1991). Point of View as a Factor of Content, in "Proceedings from Semantics and Linguistic Theory", I, Cornell Working Papers in Linguistics 10, p. 51-64, CrossRef.

Ehrlich, S. (1990). Point of View: A Linguistic Analysis of Literary Style, Routledge, London - New York, CrossRef.

Fleischman, S. (1990). Tense and Narrativity: From Medieval Performance to Modern Fiction, Routledge, London - New York.

Flundernik, M. (1999). The Fictions of Language and the Languages of Fiction. The Linguistic Representation of Speech and Consciousness, Routledge, London - New York, CrossRef.

Karttunen, L. (1991). Presupposition and Linguistic Context, in Steven Davis (ed.), Pragmatics. A Reader, Oxford University Press, New York - Oxford, p. 406-415 (first edition: 1974), CrossRef.

Kiparsky P. \& Kiparsky, C. (1971). Fact, in Danny D. Steinberg \& Leon A. Jakobovits (eds.), Semantics. An Interdisciplinary Reader in Philosophy, Linguistics and Psychology, Cambridge University Press, Cambridge, p. 345-369 (first edition: 1970), CrossRef.

Kuno, S. (1986). Blended Quasi-Direct Discourse in Japanese, paper presented at the Second SDF Workshop in Japanese Syntax, Stanford University.

Kuroda, S.-Y. (1976). Reflections on the Foundations of Narrative Theory, in T. A. van Dijk (ed.), Pragmatics of Language and Literature, North Holland, Amsterdam, p. 107-140.

Lawrence, D.H. (1934). The Rainbow, The Albatros, Hamburg - Paris - Bologna (first edition: 1915), CrossRef.

Lawrence, D. H. (1977). Women in Love, Penguin Books, Harmondsworth (first edition: 1921),

Lessing, D. (1981). To Room Nineteen, in R. V. Cassil (ed.), The Norton Anthology of Short Fiction., W. W. Norton \& Company, New York - London (first edition: 1963).

Lewis, D. (1979). Possible worlds, in Loux, 1979, p. 182-189 (first edition: 1973).

Lewis, D. (1983). Truth in Fiction, in David Lewis, Philosophical Papers, vol. I, Oxford University Press, New York - Oxford, p. 261-280 (first edition: 1978), CrossRef.

Loux, M.J. (1979). The Possible and the Actual: readings in the metaphysics of modality, Cornell University Press, Ithaca London.

McHale, B. (1978). Free Indirect Discourse: A Survey of Recent Accounts, PTL, 3(2), p. 249-287.

McHale, B. (1983). Unspeakable Sentences, Unnatural Acts: Linguistics and Poetics Revisited, in "Poetics Today", 4(1), p. 17-45, CrossRef.

Oltean, Șt. (1993). A Survey of the Pragmatic and Referential Functions of Free Indirect Discourse, in "Poetics Today", 14(4), p. 691-714, CrossRef.

Oltean, Șt. (2003). On the bivocal nature of free indirect discourse, in "Journal of Literary Semantics", 32, p. 167-176, CrossRef. Pavel, Th. G. (1986). Fictional Worlds, Harvard University Press, Cambridge, MA - London.

Portner, H. P. (2005). What is Meaning? Fundamentals of Formal Semantics, Blackwell, Oxford.

Ramazani, Vaheed (1988). The Free Indirect Mode: Flaubert and the Poetics of Irony, University Press of Virginia, Charlottesville. Rescher, Nicholas (1979). The Ontology of the Possible, in Loux, 1979, p. 166-181 (first edition: 1973).

Ron, M. (1981). Free Indirect Discourse, Mimetic Games and the Subject of Fiction, in "Poetics Today", 2(2), p. 17-39, CrossRef. Ryan, Marie-Laure (1991). Possible Worlds, Artificial Intelligence, and Narrative Theory, Indiana University Press, Bloomington - Indianapolis.

Strauch, G. (1974). De quelques interpretations récentes du style indirect libre, in "Recherches Anglaises et Américaines", 7, p. 4073.

Tarski, A. (1956). Logic, Semantics, Mathematics, Clarendon Press, Oxford.

Weinberg, H.H. (1981). Irony and "Style Indirect Libre" in Madame Bovary, in "Canadian Review of Comparative Literature", 8: 1 , p. $1-9$.

Weinberg, H.H. (1984). Centers of Consciousness Reconstructed, in "Poetics Today", 5(4), p. 767-773, CrossRef.

Woolf, V. (1964). Mrs Dalloway, Penguin Books, Harmondsworth (first edition: 1925).

Woolf, V. (1932). To the Lighthouse, The Albatros, Hamburg - Paris - Milano (first edition: 1927). 